\title{
A Chromosome Assay Method for the Detection of Heterokaryon Incompatibility (het) Genes Operating between Members of Different Heterokaryon Compatibility (h-c) Groups in Aspergillus nidulans
}

\author{
By R. B. G. DALES* AND J. H. CROFT \\ Department of Genetics, The University of Birmingham, P.O. Box 363, \\ Birmingham B15 2TT, U.K.
}

(Received 13 June 1983; revised 2 August 1983)

\begin{abstract}
Protoplast fusion has made possible the isolation of a diploid strain from haploid parents belonging to heterokaryon compatibility ( $\mathrm{h}-\mathrm{c})$ groups $\mathrm{Q}$ and $\mathrm{Gl}$ of Aspergillus nidulans. This diploid was not fully heterozygous as part, or all, of linkage group VI had achieved homozygosity. Heterokaryon compatibility tests conducted between selected pairs of parasexually derived progeny strains facilitated a chromosome assay method for the detection of heterokaryon incompatibility (het) genes. Despite the lack of segregation for the linkage group VI marker, it proved possible to locate het genes on linkage groups III, V, VI and VII. Backcross data detected five het gene differences operating between the h-cQ and h-cGl parental strains. Two het loci were located on linkage group III.
\end{abstract}

\section{INTRODUCTION}

Protoplast fusion has been successfully employed for the efficient production of heterokaryotic and diploid colonies between vegetatively (heterokaryon) incompatible strains of Aspergillus nidulans belonging to heterokaryon compatibility (h-c) groups B and 'Glasgow' (Gl) (Dales \& Croft, 1977; Dales et al., 1983). Sexual crosses between these two h-c groups have demonstrated the interaction of two nuclear heterokaryon incompatibility (het) genes, het $A$ and het $B$ (Croft \& Jinks, 1977). Parasexual analyses (Pontecorvo et al., 1953; Roper, 1966) of haploid progeny samples obtained from diploids heterozygous at either or both het $A$ or het $B$ have located these genes on linkage groups V and VI respectively (Dales et al., 1983). Compatibility tester strains were already available from the sexual cross progeny rendering the classification of compatibility of the parasexual progeny samples a relatively simple procedure.

There are 18 further h-c groups of $\boldsymbol{A}$. nidulans known to date (Croft \& Jinks, 1977). If more than two het gene differences are involved between a member of any one of these groups and a Glasgow master strain and particularly if the exact number of het gene differences is not known, then it would be difficult to locate parasexually the het genes involved by the method of compatibility tester strain classification.

The parasexual cycle involves whole chromosome reassortment during haploidization producing progeny strains which contain differential input combinations of parental chromosomes. These parental contributions can be assessed by having scoreable genetic markers on all eight linkage groups. It can be assumed that het genes and the marker gene located on the same chromosome will normally pass through the parasexual cycle unrecombined (McCully \& Forbes, 1965). Heterokaryon compatibility tests performed between pairs of parasexual progeny strains, which possess identical marker alleles for seven linkage groups and

† Present address: School of Engineering and Science, Polytechnic of Central London, 115 New Cavendish Street, London W1M 8JS, U.K.

Abbreriation: $\mathrm{Cz}$, Czapek medium. 
parental marker alleles for the remaining linkage group, should give a test for het gene location on that linkage group. If each linkage group in turn is tested in this way then this should give a rapid chromosome assay method for detecting het genes, though it will be complicated by the need for the members of each strain pair to be of different conidial coloration to facilitate heterokaryon compatibility testing (Grindle, 1963).

In this paper the results of parasexual and sexual investigations into the het gene differences between an h-cQ strain and an h-cGl master strain are presented. Sexual crosses have not previously been performed between members of these two groups and the number of het gene differences between them was unknown.

\section{METHODS}

Strains. Strains of $A$. nidulans used were the following.

7-1 biAl.

7-21 sUAladE20, yA2, adE20; acrA1; phenA2; pyroA4; lysB5; sB3; nicB8; riboB2.

7-29 pabaA6.

These strains are derivatives of NRRL 194 and are members of the 'Glasgow' heterokaryon compatibility group (h-cGl). (Gene symbols and locus letters after Clutterbuck, 1974. Strain 7-21 is master strain MSD of McCully \& Forbes, 1965.)

106-2 paba-106.1.

This strain is a UV-induced mutant derivative of wild isolate 106 in the Birmingham strain collection and has been assigned to h-cQ. (Gene symbol after Clutterbuck, 1974; locus designation is arbitrary: paba-106.1 represents the first $p$-aminobenzoic acid-requiring mutant to be isolated from wild isolate 106. It maps on linkage group I and is probably located at the pabaA locus of NRRL 194 derivatives.) Strain 106-2 was sexually crossed with strain 106-1, a yellow-sporing derivative of wild isolate 106. The absence of distinct aneuploid classes among the progeny (Pollard et al., 1968; Upshall \& Käfer, 1974) suggested that strain 106-2 was translocation-free with respect to strain 106-1, which by the same method was considered to be translocation-free with respect to isolate 106 .

Media. Czapek medium $(\mathrm{Cz})$ was routinely used as a minimal medium. Auxotrophic strains were cultured on $\mathrm{Cz}$ supplemented with the particular nutrient(s) required.

Strain culture. General culture methods and methods for the production and analysis of sexual crosses were derived from those of Pontecorvo et al. (1953) and Clutterbuck (1974). Methods for heterokaryon compatibility testing, the isolation, fusion and regeneration of protoplasts and the haploidization of diploid strains have been described previously (Dales \& Croft, 1977; Dales et al., 1983).

Throughout this paper the terms compatible and incompatible when used will mean heterokaryon compatible and heterokaryon incompatible respectively.

\section{RESULTS AND DISCUSSION}

\section{Protoplast fusion of strains 7-21 and 106-2}

Protoplast suspensions of the two parental strains were prepared, induced to fuse with polyethylene glycol and plated out on osmotically stabilized $(0.6 \mathrm{M}-\mathrm{KCl}) \mathrm{Cz}$ agar. After $3 \mathrm{~d}$ incubation at $35^{\circ} \mathrm{C}$ small colony centres were visible, most of which did not exhibit further mycelial growth on prolonged incubation but secreted a deep red pigment into the surrounding agar. Fourteen colony centres grew out with a sectoring mode of growth characteristic of balanced heterokaryons. These were extremely poorly-growing mycelial colonies bearing very few, watery, diffuse and colourless conidial heads. Heterokaryotic heads were not observed but the removal of nutritional selection led to the recovery of both parental classes only, indicating that these colonies were probably heterokaryotic.

Three hundred and fifty mycelial subcultures were made from these sectoring-growth colonies on to fresh plates of $\mathrm{Cz}$ agar. Only 18 subcultured colonies were recovered and these were composed of two distinct morphological types. The first type was characterized by a growth form of sparse mycelium totally submerged below the agar surface with no aerial hyphae or conidiophores. The mycelium developed an orange pigmentation which was secreted into the surrounding agar. The second morphological type displayed hyphal growth both above and below the agar surface. The poorly-growing mycelium possessed a pink pigmentation which was mainly cell-localized. Conidiation was limited to a few watery, diffuse and unpigmented sporeheads. This latter morphology appeared to be a derivative of the former as it was only recovered 
as sectors in colonies of the former type in 10 of the 18 successful subcultures. Initial attempts at subculturing from colonies of the first morphological type were unsuccessful, whereas the second morphological type subcultured readily growing out as symmetrically round colonies with slightly improved sporulation. Several spore-heads developed a pale green pigmentation and the spore diameters were significantly larger than the mean diameter of haploid conidia. The pink mycelial colony morphology was stable when transferred on to plates of complete medium and it was assumed that the colony type was diploid. A single culture of this presumed diploid (RD6) was retained for further analysis.

\section{Haploidization of 'diploid' strain RD6}

Mycelial transfers were made from this presumed diploid material on to fully-supplemented $\mathrm{Cz}$ agar containing benomyl to induce haploidization. These transfers produced restricted colony centres from which both green and yellow sporing sectors emanated, providing further

Table 1. Segregation of standard markers among the 222 parasexual progeny derived from the recombinant diploid RD6

This diploid strain was obtained following the protoplast fusion of strains 106-2 and 7-21. The genotype classes recovered, numbered in parentheses, and the number of strains obtained for each genotype class are presented.

\begin{tabular}{|c|c|c|c|c|c|c|c|c|c|c|}
\hline \multirow{3}{*}{$\underset{\text { phenA2 }}{\text { III }}$} & \multirow{3}{*}{$\underset{\text { pyroA4 }}{\text { IV }}$} & \multirow{3}{*}{$\begin{array}{c}\mathrm{V} \\
\text { lysB5 }\end{array}$} & \multirow{3}{*}{$\begin{array}{l}\text { VI } \\
s B 3\end{array}$} & \multirow{3}{*}{$\begin{array}{c}\text { VII } \\
\text { nic } B 8\end{array}$} & \multirow{3}{*}{$\begin{array}{c}\text { VIII } \\
\text { riboB2 }\end{array}$} & \multicolumn{5}{|c|}{$\underset{\text { I }}{\mathrm{I} a b a-106.1, y A 2}$} \\
\hline & & & & & & ${ }_{\operatorname{acrAl}}^{+}$ & $\begin{array}{r}p a b a \\
\text { II } \\
a c r\end{array}$ & $\underbrace{+}$ & $\underbrace{+}_{\text {acr }}$ & \\
\hline & & & & & & + & + & acr & + & acr \\
\hline+ & + & + & + & + & + & & (1) 6 & (2) 1 & (3) 5 & \\
\hline+ & + & + & + & + & ribo & & (4) 15 & (5) 9 & (6) 13 & (7) 5 \\
\hline+ & + & + & + & nic & + & (8) 1 & & (9) 1 & (10) 1 & (11) 2 \\
\hline+ & + & + & + & nic & ribo & & (12) 4 & (13) 5 & (14) 6 & (15) 1 \\
\hline+ & + & lys & + & + & + & & (16) 1 & & (17) 1 & \\
\hline+ & + & lys & + & + & ribo & & (18) 1 & & (19) 1 & \\
\hline+ & + & lys & + & nic & + & & & & & \\
\hline+ & + & lys & + & nic & ribo & & (20) 1 & & & \\
\hline+ & pyro & + & + & + & + & & (21) 7 & (22) 3 & (23) 3 & (24) 4 \\
\hline+ & pyro & + & + & + & ribo & & (25) 12 & (26) 6 & (27) 7 & (28) 6 \\
\hline+ & pyro & + & + & nic & + & & (29) 3 & (30) 5 & (31) 2 & (32) 3 \\
\hline+ & pyro & + & + & nic & ribo & & (33) 11 & (34) 2 & (35) 9 & (36) 2 \\
\hline+ & pyro & lys & + & + & + & & (37) 1 & & & \\
\hline+ & pyro & lys & + & + & ribo & & & (38) 1 & (39) 1 & (40) 1 \\
\hline+ & pyro & lys & + & nic & + & & & (41) 1 & & \\
\hline+ & pyro & lys & + & nic & ribo & & (42) 1 & (43) 3 & (44) 1 & (45) 1 \\
\hline phen & + & + & + & + & + & & & & (46) 1 & \\
\hline phen & + & + & + & + & ribo & & (47) 2 & (48) 2 & (49) 1 & \\
\hline phen & + & + & + & nic & + & & & (50) 1 & & \\
\hline phen & + & + & + & $n i c$ & ribo & & (51) 5 & (52) 1 & (53) 1 & (54) 1 \\
\hline phen & + & lys & + & + & + & & & & & \\
\hline phen & + & lys & + & + & ribo & & (55) 1 & & (56) 1 & (57) 1 \\
\hline phen & + & lys & + & nic & + & & & & & \\
\hline phen & + & lys & + & nic & ribo & & (58) 2 & & & \\
\hline phen & pyro & + & + & + & + & & (59) 1 & $(60) 1$ & & \\
\hline phen & pyro & + & + & + & ribo & & (61) 1 & (62) 1 & (63) 3 & (64) 2 \\
\hline phen & pyro & + & + & nic & + & & (65) 5 & (66) 1 & & \\
\hline phen & pyro & + & + & nic & ribo & & (67) 1 & (68) 1 & 3 & (70) 1 \\
\hline phen & pyro & lys & + & + & + & & & & & \\
\hline phen & pyro & lys & + & + & ribo & & (71) 1 & & (72) 2 & \\
\hline phen & pyro & lys & + & nic & + & & & & (73) 1 & \\
\hline phen & pyro & lys & + & nic & ribo & & & & & (74) 1 \\
\hline
\end{tabular}


Table 2. Heterokaryon compatibility tests selected to test for het gene interaction on linkage group I within the RD6 diploid

\begin{tabular}{|c|c|c|c|}
\hline $\begin{array}{l}\text { Linkage group } \\
\text { under test }\end{array}$ & $\begin{array}{l}\text { Strain } \\
\text { pair }\end{array}$ & $\begin{array}{l}\text { Genotype } \\
\text { class* }\end{array}$ & $\begin{array}{c}\text { Compatibility } \\
\text { test }\end{array}$ \\
\hline \multirow{9}{*}{ I \{} & $\left\{\begin{array}{l}\text { RD6-4 } \\
\text { RD6-143 }\end{array}\right.$ & $\begin{array}{l}3 \\
1\end{array}$ & + \\
\hline & $\left\{\begin{array}{l}\text { RD6-8 } \\
\text { RD6-150 }\end{array}\right.$ & $\begin{array}{l}3 \\
1\end{array}$ & + \\
\hline & $\left\{\begin{array}{l}\text { RD6-21 } \\
\text { RD6-130 }\end{array}\right.$ & $\begin{array}{l}6 \\
4\end{array}$ & - \\
\hline & $\left\{\begin{array}{l}\text { RD6-6 } \\
\text { RD6-134 }\end{array}\right.$ & $\begin{array}{l}7 \\
5\end{array}$ & + \\
\hline & $\left\{\begin{array}{l}\text { RD6-16 } \\
\text { RD6-137 }\end{array}\right.$ & $\begin{array}{l}23 \\
21\end{array}$ & + \\
\hline & $\left\{\begin{array}{l}\text { RD6-15 } \\
\text { RD6-157 }\end{array}\right.$ & $\begin{array}{l}35 \\
33\end{array}$ & + \\
\hline & $\left\{\begin{array}{l}\text { RD6-33 } \\
\text { RD6-170 }\end{array}\right.$ & $\begin{array}{l}27 \\
25\end{array}$ & + \\
\hline & $\left\{\begin{array}{l}\text { RD6-3 } \\
\text { RD6-183 }\end{array}\right.$ & $\begin{array}{l}44 \\
42\end{array}$ & + \\
\hline & $\left\{\begin{array}{l}\text { RD6-42 } \\
\text { RD6-221 }\end{array}\right.$ & $\begin{array}{l}69 \\
67\end{array}$ & + \\
\hline
\end{tabular}

evidence for the diploid nature of the RD6 material. A progeny sample of 222 haploid segregants (RD6-1 to RD6-222) was collected. The segregants were purified, transferred to $4 \times 4$ master plates and replicated on to a range of differential media to analyse the segregation of standard markers (Table 1).

It can be seen that all 222 progeny strains were wild-type with respect to the $s B$ marker on linkage group VI. Presumably heterozygosity for this chromosome had been lost prior to haploidization of the diploid and could be due to mitotic crossing-over or chromosomal nondisjunction (Käfer, 1961) as was observed within the range of diploids produced from strains belonging to the h-cB and h-cGl groups (Dales et al., 1983). Unless chromosome VI is naturally predisposed to genetical recombination it must be assumed that heterozygosity for this chromosome imparts a strong selection pressure favouring the removal of that heterozygosity. This could indicate the interaction of unlike alleles at a single het locus, or possibly several het loci, between the parental strains on linkage group VI. This was shown to be the case with the $\mathrm{h}-\mathrm{cB} / \mathrm{h}-\mathrm{cGl}$ diploid where prior to recombination of linkage group VI, heterozygous het $B$ alleles were operative (Dales et al., 1983). As the RD6 material was of a recombinant diploid nature it would seem reasonable to suggest that the first morphological type, described from the 18 successful transfers, was the fully heterozygous diploid.

The unlinked standard markers on the seven remaining linkage groups displayed segregation patterns among the progeny indicating the absence of gross chromosomal translocations within the parental $\mathrm{h}-\mathrm{cQ}$ and $\mathrm{h}-\mathrm{cGl}$ strains, though marked deviations from expected ratios were recovered. Low frequencies of the mutant alleles of the phen $A$, lys $B$ and acr $A$ genes and the wildtype allele of the riboB gene were obtained. This could have been due to sampling error compounded with low allele viability, particularly for the mutant alleles of the phen $A$ and $l y s B$ genes, as reduced viability is commonly observed in both sexual and parasexual crosses involving these markers.

\section{Test for het gene location on linkage group I}

Disturbed segregation ratios were not expected to impede further analysis. Nine pairs of progeny strains were selected to test for het gene location on linkage group I. Each strain pair possessed identical alleles for the markers on linkage groups II to VIII and alternative alleles for 
Table 3. Heterokaryon compatibility tests selected to test for het gene interaction on linkage groups $I I I, I V, V, V I I$ and VIII within the RD6 diploid

\begin{tabular}{|c|c|c|c|c|c|c|c|}
\hline $\begin{array}{l}\text { Linkage group } \\
\text { under test }\end{array}$ & $\begin{array}{c}\text { Strain } \\
\text { pair }\end{array}$ & $\begin{array}{l}\text { Genotype } \\
\text { class* }\end{array}$ & Compatibility & $\begin{array}{l}\text { Linkage group } \\
\text { under test }\end{array}$ & $\begin{array}{c}\text { Strain } \\
\text { pair }\end{array}$ & $\begin{array}{l}\text { Genotype } \\
\text { class* }\end{array}$ & $\begin{array}{c}\text { Compatibility } \\
\text { test }\end{array}$ \\
\hline \multirow{7}{*}{ II } & $\left\{\begin{array}{l}\text { RD6-4 } \\
\text { RD6-154 }\end{array}\right.$ & $\begin{array}{l}3 \\
2\end{array}$ & + & \multirow{7}{*}{ V } & $\left\{\begin{array}{l}\text { RD6-24 } \\
\text { RD6-143 }\end{array}\right.$ & $\begin{array}{r}17 \\
1\end{array}$ & - \\
\hline & $\left\{\begin{array}{l}\text { RD6-6 } \\
\text { RD6-130 }\end{array}\right.$ & $\begin{array}{l}7 \\
4\end{array}$ & + & & $\left\{\begin{array}{l}\text { RD6-50 } \\
\text { RD6-130 }\end{array}\right.$ & $\begin{array}{r}19 \\
4\end{array}$ & - \\
\hline & $\left\{\begin{array}{l}\text { RD6-41 } \\
\text { RD6-202 }\end{array}\right.$ & $\begin{array}{r}10 \\
9\end{array}$ & + & & $\left\{\begin{array}{l}\text { RD6-2 } \\
\text { RD6-222 }\end{array}\right.$ & $\begin{array}{l}14 \\
20\end{array}$ & - \\
\hline & $\left\{\begin{array}{l}\text { RD6-26 } \\
\text { RD6-137 }\end{array}\right.$ & $\begin{array}{l}24 \\
21\end{array}$ & + & & $\left\{\begin{array}{l}\text { RD6-4 } \\
\text { RD6-148 }\end{array}\right.$ & $\begin{array}{r}3 \\
16\end{array}$ & - \\
\hline & $\left\{\begin{array}{l}\text { RD6-15 } \\
\text { RD6-186 }\end{array}\right.$ & $\begin{array}{l}35 \\
34\end{array}$ & + & & $\left\{\begin{array}{l}\text { RD6-3 } \\
\text { RD6-157 }\end{array}\right.$ & $\begin{array}{l}44 \\
33\end{array}$ & - \\
\hline & $\left\{\begin{array}{l}\text { RD6-30 } \\
\text { RD6-143 }\end{array}\right.$ & $\begin{array}{r}46 \\
1\end{array}$ & - & & $\left\{\begin{array}{l}\text { RD6-41 } \\
\text { RD6-143 }\end{array}\right.$ & $\begin{array}{r}10 \\
1\end{array}$ & - \\
\hline & $\left\{\begin{array}{l}\text { RD6-81 } \\
\text { RD6-130 }\end{array}\right.$ & $\begin{array}{r}49 \\
4\end{array}$ & - & & $\left\{\begin{array}{l}\text { RD6-2 } \\
\text { RD6-130 }\end{array}\right.$ & $\begin{array}{r}14 \\
4\end{array}$ & - \\
\hline \multirow[t]{5}{*}{ III } & $\left\{\begin{array}{l}\text { RD6-1 } \\
\text { RD6-179 }\end{array}\right.$ & $\begin{array}{l}11 \\
50\end{array}$ & - & \multirow[t]{5}{*}{ VII } & $\left\{\begin{array}{l}\text { RD6-1 } \\
\text { RD6-154 }\end{array}\right.$ & $\begin{array}{r}11 \\
2\end{array}$ & - \\
\hline & $\left\{\begin{array}{l}\text { RD6-16 } \\
\text { RD6-155 }\end{array}\right.$ & $\begin{array}{l}23 \\
59\end{array}$ & - & & $\left\{\begin{array}{l}\text { RD6-52 } \\
\text { RD6-137 }\end{array}\right.$ & $\begin{array}{l}31 \\
21\end{array}$ & - \\
\hline & $\left\{\begin{array}{l}\text { RD6-15 } \\
\text { RD6-221 }\end{array}\right.$ & $\begin{array}{l}35 \\
67\end{array}$ & - & & $\left\{\begin{array}{l}\text { RD6-15 } \\
\text { RD6-170 }\end{array}\right.$ & $\begin{array}{l}35 \\
25\end{array}$ & - \\
\hline & $\left\{\begin{array}{l}\text { RD6-16 } \\
\text { RD6-143 }\end{array}\right.$ & $\begin{array}{r}23 \\
1\end{array}$ & + & & $\left\{\begin{array}{l}\text { RD6-41 } \\
\text { RD6-132 }\end{array}\right.$ & $\begin{array}{l}10 \\
12\end{array}$ & + \\
\hline & $\left\{\begin{array}{l}\text { RD6-33 } \\
\text { RD6-130 }\end{array}\right.$ & $\begin{array}{r}27 \\
4\end{array}$ & + & & $\left\{\begin{array}{l}\text { RD6-21 } \\
\text { RD6-143 }\end{array}\right.$ & $\begin{array}{l}6 \\
1\end{array}$ & - \\
\hline \multirow[t]{3}{*}{ IV \{} & $\left\{\begin{array}{l}\text { RD6-41 } \\
\text { RD6-129 }\end{array}\right.$ & $\begin{array}{l}10 \\
29\end{array}$ & + & \multirow[t]{3}{*}{ VIII } & $\left\{\begin{array}{l}\text { RD6-6 } \\
\text { RD6-154 }\end{array}\right.$ & $\begin{array}{l}7 \\
2\end{array}$ & + \\
\hline & $\left\{\begin{array}{l}\text { RD6-2 } \\
\text { RD6-157 }\end{array}\right.$ & $\begin{array}{l}14 \\
33\end{array}$ & + & & $\left\{\begin{array}{l}\text { RD6-33 } \\
\text { RD6-137 }\end{array}\right.$ & $\begin{array}{l}27 \\
21\end{array}$ & + \\
\hline & $\left\{\begin{array}{l}\text { RD6-26 } \\
\text { RD6-154 }\end{array}\right.$ & $\begin{array}{r}24 \\
2\end{array}$ & + & & $\left\{\begin{array}{l}\text { RD6-15 } \\
\text { RD6-129 }\end{array}\right.$ & $\begin{array}{l}35 \\
29\end{array}$ & + \\
\hline
\end{tabular}

the markers on linkage group I. As the members of each pair were therefore of different conidial coloration they could be readily tested for compatibility. The standard marker genotype classes of the progeny strain pairs and the results of the compatibility tests are presented in Table 2 . Eight of the nine pairs were heterokaryon compatible, and one pair (RD6-21 with RD6-130) was incompatible. These.results strongly suggest that there are no het gene differences between the parental strains 7-21 and 106-2 on linkage group I. The single negative result can be explained if a mitotic crossing-over event had recombined the marker and het loci on a het gene bearing linkage group, other than linkage group I, in either strain RD6-21 or strain RD6-130.

\section{Tests for het gene location on linkage groups II to VIII}

The probability that there were no het genes located on linkage group I facilitated the analysis of the RD6 progeny without the necessity to induce spore colour mutations in progeny strains. Pairs of progeny strains were selected which possessed unlike marker alleles on linkage group I, furnishing the necessary conidial colour difference for compatibility testing, and which possessed unlike marker alleles for each of the remaining linkage groups in turn, with the exception of linkage group VI which could not be tested in this way. Within each test pairing the remaining six linkage groups possessed identical marker alleles and for each linkage group under test five different pairwise compatibility comparisons were performed. The results of this chromosome assay for detection of het genes are presented in Table 3. The results indicate that 
Table 4. Sexual crosses designed to elucidate the number of het gene differences operating on linkage groups III, V, VI and VII between strains 106-2 and 7-21, of $Q$ and $G 1$ compatibility respectively

\begin{tabular}{|c|c|c|c|c|c|c|}
\hline \multirow{2}{*}{$\begin{array}{c}\text { Cross } \\
\text { no. }\end{array}$} & \multirow[b]{2}{*}{ Strains* } & \multirow{2}{*}{$\begin{array}{l}\text { Linkage groups } \\
\text { under test }\end{array}$} & \multicolumn{2}{|c|}{$\begin{array}{l}\text { Total no. of progeny strains } \\
\text { in compatibility classes } \dagger \text { : }\end{array}$} & \multirow{2}{*}{$\begin{array}{c}\text { No. of } \\
\text { het gene } \\
\text { differences }\end{array}$} & \multirow{2}{*}{$\begin{array}{c}\text { Linkage group } \\
\text { locations }\end{array}$} \\
\hline & & & Parental & Recombinant & & \\
\hline RD7 & $\begin{array}{l}\text { RD6-64 } \times 7-1 \\
(74)\end{array}$ & VI & 46,54 & & 1 & VI \\
\hline RD8 & $\begin{array}{l}\text { RD6-93 } \\
\quad(45)\end{array}$ & III and VI & 12,20 & $11,18,12,16,8,3$ & 3 & VI, III, III \\
\hline RD9 & $\begin{array}{l}\text { RD6-80 } \\
(70)\end{array}$ & $\mathrm{V}$ and $\mathrm{VI}$ & 17,36 & 18,29 & 2 & VI, V \\
\hline RD10 & $\begin{array}{l}\text { RD6-67 } \\
(72)\end{array}$ & VI and VII & 24,23 & 25,28 & 2 & VI, VII \\
\hline
\end{tabular}

allelic differences for het loci were operative between the parental strains 7-21 and 106-2 on linkage groups III, V and VII and thus the minimum number of het gene differences between $\mathrm{h}-\mathrm{cQ}$ and $\mathrm{h}-\mathrm{cGl}$ is three, though more than one het gene may be active on any of these three linkage groups. het gene location on linkage group VI is also possible if the argument put forward for the selection of the products of recombinational events for this chromosome is correct.

The tests for het gene location on linkage group VIII gave four positive results and one negative. It should be noted that this negative result and the previous inconsistent result, obtained with the linkage group I tests, have both involved strain RD6-21. It would seem likely that this strain has either been genotyped incorrectly or been produced as a result of mitotic recombination on one of linkage groups III, V (possibly VI) or VII.

\section{Detection of het gene location on linkage group VI}

Strain RD6-64, genotype class 74, was compatibility tested with h-cGl strain 7-1. The result of this test was negative providing evidence of het gene activity on linkage group VI.

\section{Determination of the total number of het genes operating on linkage groups III, V, VI and VII}

Selected RD6 progeny strains were backcrossed to h-cGl strains, progeny samples collected and compatibility tested. The results are presented in Table 4 . It can be seen that there are five het gene differences operating between strains of $\mathrm{h}-\mathrm{cQ}$ and $\mathrm{h}-\mathrm{cGl}$. A single het gene is present on each of linkage groups V, VI and VII and two het genes on linkage group III.

Further backcrosses were made of selected RD7, RD8, RD9 and RD10 progeny strains with $\mathrm{h}-\mathrm{cGl}$ strains (data not shown) to provide strains of h-cGl genetic background bearing individual het alleles derived from the original $\mathrm{h}-\mathrm{cQ}$ parental strain 106-2. The five strain classes produced were compatibility tested in all possible pairwise combinations. All tests gave negative results confirming that five distinct het gene allelic differences had been detected between the parental strains of $\mathrm{h}-\mathrm{cQ}$ and $\mathrm{h}-\mathrm{cGl}$.

The parasexual analysis of the RD6 diploid has provided circumstantial information on the genome organization of the $h-c Q$ parental strain. The wild-type alleles of strain 106-2, which are alternative alleles to the unlinked marker genes derived from strain 7-21, segregated in an unlinked manner among the RD6 progeny indicating that the overall genome organization of the $\mathrm{h}-\mathrm{cQ}$ and $\mathrm{h}-\mathrm{cGl}$ strains is probably similar.

It has proved possible to complete the analysis of het gene segregation among the RD6 parasexual progeny despite the fact that linkage group VI had become partly, or totally, homozygous prior to haploidization. This genome instability, which is currently under investigation, made the subsequent analysis of backcross progeny more complicated though the number of het gene differences operating between a strain of h-cQ and an h-cGl strain could still 
be deduced. This methodology will be used to investigate the heterokaryon compatibility relationships of further $\mathrm{h}-\mathrm{c}$ groups.

We acknowledge the Science Research Council for the award of a research studentship to R. B.G.D. and of a research grant to J.H.C.

\section{REFERENCES}

Clutterbuck, A. J. (1974). Aspergillus nidulans. In Handbook of Genetics, vol. 1, pp. 447-510. Edited by R. C. King. New York: Plenum Press.

CROFT, J. H. \& Jinks, J. L. (1977). Aspects of the population genetics of Aspergillus nidulans. In Genetics and Physiology of Aspergillus, pp. 339-360. Edited by J. E. Smith \& J. A. Pateman. London: Academic Press.

Dales, R. B. G. \& Croft, J. H. (1977). Protoplast fusion and the isolation of heterokaryons and diploids from vegetatively incompatible strains of Aspergillus nidulans. FEMS Microbiology Letters 1, 201-204.

Dales, R. B. G., Moorhouse, J. \& Croft, J. H. (1983). The location and analysis of two heterokaryon incompatibility (het) loci in strains of Aspergillus nidulans. Journal of General Microbiology 129, 3637-3642.

GRINDLE, M. (1963). Heterokaryon compatibility of unrelated strains in the Aspergillus nidulans group. Heredity 18, 191-204.

KÄFER, E. (1961). The process of spontaneous recom- bination in vegetative nuclei of Aspergillus nidulans. Genetics 46, 1581-1609.

MCCully, K. S. \& Forbes, E. (1965). The use of $p$ fluorophenylalanine with 'master strains' of Aspergillus nidulans for assigning genes to linkage groups. Genetical Research 6, 352-359.

Pollard, R., KäFer, E. \& Johnston, M. (1968). Influence of chromosomal aberrations on meiotic and mitotic non-disjunction in Aspergillus nidulans. Genetics 60, 743-757.

Pontecorvo, G., Roper, J. A., Hemmons, L. M., Macdonald, K. D. \& Bufton, A. W. J. (1953). The genetics of Aspergillus nidulans. Advances in Genetics 5, 141-238.

ROPER, J. A. (1966). Mechanisms of inheritance: the parasexual cycle. In The Fungi, vol. 2, pp. 589-617. Edited by G. C. Ainsworth \& A. S. Sussman. New York: Academic Press.

UPSHALl, A. \& KäFER, E. (1974). Detection and identification of translocations by increased specific non-disjunction in Aspergillus nidulans. Genetics 76, 19-31. 